\title{
Endophytic Fungi, Drechs/era spicifera, Mediated Synthesis of Biogenic Silver Nanoparticles
}

\author{
Sharada Laxman Deore, Bhushan Arun Baviskar, Preeti N Sonar, Anjali Ashokarao Kide, \\ Bhavana Ashokarao Shende
}

Government College of Pharmacy, Amravati, Maharashtra, INDIA

\begin{abstract}
Aim: In present communication, endophytic fungi Drechslera spicifera is isolated from leaves of Cardiospermum halicacabum and used as a reducing agent for silver nanoparticles (AgNPs) synthesis. Materials and Methods: Synthesized AgNPs were characterised using UV-vis spectroscopy, FTIR, scanning-electron microscopy (SEM) and particle size analysis. Total phenolic, flavonoid content and antioxidant potential of endophytic fungi (culture and aqueous extract), host plant Cardiospermum halicacabum (methanol and aqueous extracts) and silver nanoparticles (culture and aqueous extract mediated silver nanoparticles) was determined. Results and Conclusion: The endophytic fungi Drechslera spicifera forms stable AgNPs and also showed good antioxidant potential for pharmaceutical applications.
\end{abstract}

Key words: Cardiospermum halicacabum, Drechslera spicifera, Endophytic fungi, Silver nanoparticle, Antioxidant.

\section{INTRODUCTION}

Nanotechnology refers to the engineered materials at the molecular scale. There are various approaches to nanoparticle synthesis like physical, chemical and biological. A biological method involves use of number of organisms like bacteria, fungi, algae, viruses or plants. A number of fungi have been described in the literature to produce gold, silver, magnetite, titania, zirconia nanoparticles. ${ }^{1}$ Endophytic fungi live within healthy plant host without causing any apparent infection and have been documented to provide a number of benefits to the host throughout its life. These endophytes are a valuable resource for green chemistry route of nanoparticle biosynthesis, as a million of them exist in plants. But Colletotrichum, Pestalotia and Penicillium are the only endophytes that have been documented to produce silver nanoparticles from Pelargonium graveolens, cumini (L), Centella asiatica respectively while $A$. clavatus used for gold and silver from Azadiracbta indica. ${ }^{2}$
Drechslera spicifera (teleomorph: Cocbliobolus spicifer is distributed worldwide and occurs mainly in tropical and subtropical regions. This fungus was first named as Brachucladium spoiciferum in 1908, renamed as Curvularia spicifera in 1933, then Helminthosporiun spiciferum in 1953, followed by Drechslera spicifera in 1970 and renamed again as B. spicifera by Subramanian in 1971.,4 Drechslera spicifera is a Class 3 endophytes as they belongs to Ascomycota - Dothideomycetes family which are horizontally transmitted by wind, rain and insects and are mainly found in the foliage of tropical climates. Amravati of Maharashtra has a suitable climatic condition for Drecbslera species to exist in endophytic association in plants like Cardiospermum halicacabum L. It has been previously reported the existence of this fungi as an endophyte in Ficus religiosa and F. benghalensis. Bipolaris spicifera and Drechslera halodes were some of endophytes
Submission Date: 23-10-2020; Revision Date: 24-12-2020; Accepted Date: 12-04-2021

DOI: 10.5530/ijper.55.2s.126 Correspondence: Dr. Sharada Laxman Deore Government College of Pharmacy, Amravati-444 604, Maharashtra, INDIA.

Phone no: +91-9766577646 Email id: sharudeore_2@ yahoo.com

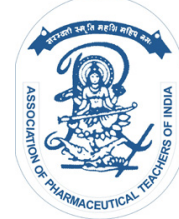

www.ijper.org 
among 645 isolates from cheat grass which were not associated with fire or heat tolerance. ${ }^{5,6}$

In present communication first time silver nanoparticles are prepared by endophytic fungi named Drechslera spicifera. This nanoparticle formation process, its confirmation and characterization and reaction monitoring have been elaborated in this paper. A number of literatures reported confirmation of nanoparticle formation by UV-visible spectroscopy only where complete reduction of metal salt solution is detected. But in present communication, we have tried to use FTIR analysis of nanoparticle aliquot, to associate the spectral data with various functional groups excreted by the fungi in nanoparticle formation process and their involvement in the same.

Total phenolic, flavonoid content and antioxidant potential of endophytic fungi (culture and aqueous extract), host plant Cardiospermum belicacabum (methanol and aqueous extracts) and silver nanoparticles (culture and aqueous extract mediated silver nanoparticles) was estimated using Folin - Ciocalteau method, Alumnium Chloride method and 1,1-diphenyl-2-picrylhydrazyl free radical scavenging in vitro method respectively.

\section{MATERIALS AND METHODS}

Fungi Isolation and its identification: The fresh leaves of Cardiospermum halicacabum Linn. were collected from Amravati city (Maharashtra). The plant was authenticated by HOD, Department of Botany, Government Vidarbha Institute of Science and Humanities, Amravati. The leaves of Cardiospermum halicacabum were first washed and cleaned in sterilized distilled water, followed by surface sterilization of small pieces with $0.5 \%$ sodium hypochlorite and washed thoroughly with sterile distilled water. The surface sterilized leaf segments were evenly spaced in petri dishes $(9 \mathrm{~cm}$ diameter) containing potato dextrose agar (PDA) medium and incubated at $26 \pm 1^{\circ} \mathrm{C}$. The hyphal tips which grew out from leaf segments after 20 days were isolated and identified using standard monographs. ${ }^{7}$ Endophyte was identified and authenticated as Drechslera spicifera by Indian Type Culture Collection Centre, New Delhi.

Preparation of solutions: Culture extract: For the synthesis of the silver nanoparticles, $1 \times 10^{6}$ conidia of D. spicifera were inoculated in $500 \mathrm{ml}$ Erlenmeyer flasks containing $200 \mathrm{ml}$ MGYP medium which is composed of malt extract $(0.3 \%)$, glucose $(1 \%)$, yeast extract $(0.3 \%)$ and peptone $(0.5 \%)$. The culture was grown under continuous shaking on a rotary shaker $(200 \mathrm{rpm})$ at 25-27C for $120 \mathrm{hr}$. After $120 \mathrm{hr}$ of fermentation, biomasses were separated from the culture broth by filtration through sterile muslin cloth and then the biomass was washed thrice with sterile distilled water under sterile conditions. The harvested mycelial mass (15 gm of wet mycelia) was then suspended in $100 \mathrm{ml}$ of 10-3 $\mathrm{M}$ aqueous $\mathrm{AgNO}_{3}$ solution in $500 \mathrm{~mL}$ Erlenmeyer flasks. The whole mixture was maintained in the dark into a shaker at $25-27^{\circ} \mathrm{C}(200 \mathrm{rpm})$. The bioreduction of the $\mathrm{AgNO}_{3}$ ions in solutions was monitored for any color changes in cell or solution. $10 \mathrm{~g}$ of wet mycelia was then re-suspended in $100 \mathrm{ml}$ of sterile distilled water which is used as a control and 10-3 $\mathrm{M}$ aqueous $\mathrm{AgNO}_{3}$ as a blank and used for the next set of experiments. The cells were dehydrated and fixed with glutaraldehyde and sent for SEM with EDS analysis.

Aqueous extract: The additional $10 \mathrm{gm}$ of wet biomass obtained in step 2 is suspended in $100 \mathrm{ml}$ of sterile distilled water and incubated for 5 days. The aqueous extract was filtered with sterile muslin cloth and used for the next set of experiments.

\section{Preliminary phytochemical screening of fungal extract}

Phytochemical screening of crude extracts performed to analyze presence of various secondary metabolites such as alkaloids, phenols, flavonoids, steroids, terpenoids, saponins, tannins. ${ }^{8}$

\section{Determination of total phenolic content}

Total phenol content of extracts endophytic fungi (culture and aqueous extract), host plant Cardiospermum halicacabum (methanol and aqueous extracts) was estimated using Folin Ciocalteau reagent based assay using gallic acid as standard. Each extract $(1 \mathrm{mg} / \mathrm{mL})$ of $100 \mu \mathrm{l}$ was added with $500 \mu \mathrm{L}$ of $1 \mathrm{~N}$ Folin - Ciocalteau reagent. Then $1.5 \mathrm{~mL}$ of $20 \%$ of $\mathrm{NaCO}_{3}$ was added to the mixture. Final volume was made $5 \mathrm{~mL}$ by adding distilled water. The mixture was incubated for $30 \mathrm{~min}$ at room temperature and the absorbance of the developed colour was recorded at $765 \mathrm{~nm}$ using UV-vis spectrophotometer. The same procedure was done with $1 \mathrm{~mL}$ aliquot of 5,10 to $50 \mu \mathrm{g} / \mathrm{mL}$ gallic acid were used as standard for calibration curve. ${ }^{9}$

\section{Determination of total flavonoid content}

Total flavonoid content of extracts endophytic fungi (culture and aqueous extract), host plant Cardiospermum halicacabum (methanol and aqueous extracts) was estimated using Aluminium chloride colorimetric method. The extract $(1 \mathrm{mg} / \mathrm{mL})$ of $100 \mu \mathrm{l}$ was mixed with $2 \mathrm{~mL}$ of distilled water and $0.15 \mathrm{~mL}$ of $5 \% \mathrm{NaNO}_{2}$ solution. Then after 6 min, $0.15 \mathrm{~mL}$ of $10 \% \mathrm{AlCl}_{3}$ of was added and the mixture was allowed to stand for another $6 \mathrm{~min}$, then $2 \mathrm{~mL}$ of $4 \% \mathrm{NaOH}$ solution was added. The final volume was made up to $5 \mathrm{~mL}$ by adding distilled water 
immediately and the mixture was allowed to stand for $15 \mathrm{~min}$ at room temperature. Absorbance was recorded at $510 \mathrm{~nm}$ using UV-vis spectrophotometer. Rutin was used as a standard compound for quantification of flavonoid and the results were expressed as rutin equivalents (RE). ${ }^{9}$

In vitro antioxidant activity: DPPH free radical scavenging method is used for determination of in vitro antioxidant potential of endophytic fungi (culture and aqueous extract), host plant Cardiospermum balicacabum (methanol and aqueous extracts) extracts and two types of (culture and aqueous mediated) silver nanoparticles. $1 \mathrm{ml}$ different concentration of extract solution and standard were taken in different vials. To this $5 \mathrm{ml}$ of methanolic solution of DPPH was added, shaken well and mixture was incubated at $37^{\circ} \mathrm{C}$ for $20 \mathrm{~min}$. The absorbance was measured against methanol as blank at $516 \mathrm{~nm}$. Absorbance of DPPH was taken as control. ${ }^{9}$

Synthesis of silver Nanoparticles: $20 \mathrm{ml}$ of culture extract was withdrawn and $\mathrm{pH}$ of the solution was adjusted to 9 with $1 \%$ sodium carbonate. This solution was reacted with $80 \mathrm{ml}$ of $1 \mathrm{mM}$ silver nitrate in dark under stationary conditions at alkaline $\mathrm{pH} 9(\mathrm{R})$. The $\mathrm{pH}$ of $20 \mathrm{ml}$ of aqueous extract also was adjusted to 9 with $1 \%$ sodium carbonate and $80 \mathrm{ml}$ of $1 \mathrm{mM}$ silver nitrate was kept in stationary condition $\left(\mathrm{R}_{\mathrm{t}}\right)$ in dark. All experiments were conducted in triplicate. Same procedure followed for aqueous extract. The aqueous extract mediated nanoparticles were separated by centrifugation at $6000 \mathrm{rpm}$ for $10 \mathrm{~min}$ till pellet left behind, followed by washing in distilled water. The brown supernatant obtained after centrifugation was separated from the pellet. ${ }^{10}$ Both culture and aqueous extract mediated silver nanoparticle samples were preserved further analysis.

Characterization of silver nanoparticles: The confirmation of nanoparticle formation was done on basis of visual colour change. ${ }^{10}$ Physicochemical characterization of silver nanoparticles was done by UV-vis spectroscopy (Shimadzu- UV 1700), FTIR spectroscopy (ShimadzuIR affinity 1), FESEM (HR), particle size analysis and zeta potential measurements

\section{RESULTS AND DISCUSSION}

Fungi identification and culturing: The fungi which grew over surface sterilized leaf was isolated and cultured in PDA and purified 5 times till a single isolate was obtained. Three fungal species were isolated of which one is identified as D. spicifera [Figure 1] by Indian Type Culture Collection Centre, New Delhi and used further. Two extracts were prepared one is culture extract

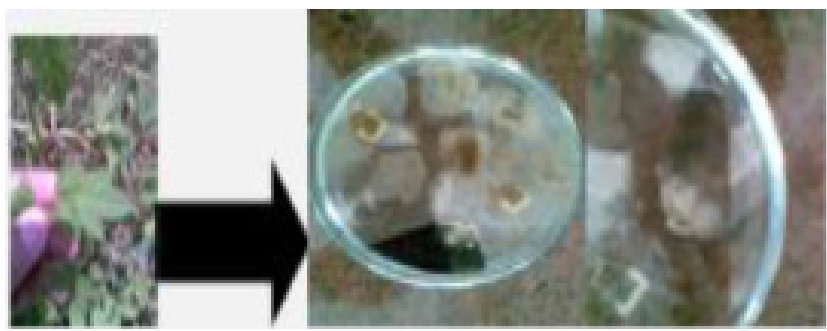

Figure 1: Image of fungi growing over the surface of leaf segment.

containing fungi and another aqueous extract which was not containing fungi.

\section{Phytochemical screening}

Preliminary phytochemical screening reveals that plant contains various types of phytoconstituents which are carbohydrate, alkaloid, saponin, flavonoid, tannin. [Table 1] Whereas protein, glycoside, steroid, gum, mucilage, fatty oil and essential oil component seems to be absent. Preliminary phytochemical screening gives idea about the qualitative nature of active phytoconstituent present in the whole plant alcoholic and aqueous extract.

\section{Determination of Total phenolic and flavonoid content}

Good amount of total phenolic and flavonoid content is found in host plant as well as endophytic fungal extracts. The results were presented in Table 2. Host plant is found to have more phenolic and flavonoid content compared to endophytic fungi.

\section{In vitro antioxidant activity}

DPPH [1, 1-Diphenyl-2-picryl hydrazyl] is a stable free radical, which shows absorbance at $517 \mathrm{~nm}$. The antioxidant reacts with DPPH and converts it to 1, 1-Diphenyl-2-picryl hydrazine which do not absorb at $517 \mathrm{~nm}$. Lower absorbance of the reaction mixture indicated higher free radical activity. Biogenic silver nanoparticles found to have more antioxidant potential compared to host plant and endophytic fungi while endophytic fungi have slightly lower antioxidant potential compared to host plant [Table 3].

Synthesisand Characterizationof Silvernanoparticles: In the present study the culture extract and the cell free aqueous extract of D. spicifera was mixed with aqueous solution of the silver ion complex to form silver nanoparticles. Synthesised nanaopartilces are characterized by visual colour change as shown in Figure 2 and UV-Visible spectroscopy ${ }^{11}$ as reported in Figure 3. FTIR analysis ${ }^{11}$ as shown in Figure 4 performed to detect functional group changes and thus mode of action of silver nanoparticle synthesis. Particle size measured to 


\section{Table 1: Results of phytochemical screening of extracts from host plant- $C$. halicacabum and endophytic} fungi- D. spicifera.

\begin{tabular}{|c|c|c|c|c|}
\hline $\begin{array}{l}\text { Sample /Phytochemicals } \\
\text { and tests }\end{array}$ & $\begin{array}{l}\text { Endophytic fungi- } \\
\text { D. spicifera culture } \\
\text { extract }\end{array}$ & $\begin{array}{l}\text { Endophytic fungi- } \\
\text { D. spicifera aqueous } \\
\text { extract }\end{array}$ & $\begin{array}{l}\text { C. halicacabum } \\
\text { aqueous extracts }\end{array}$ & $\begin{array}{c}\text { C. halicacabum } \\
\text { methanol extracts }\end{array}$ \\
\hline $\begin{array}{l}\text { Carbohydrates } \\
\text { - Molish test } \\
\text { - } \quad \text { Fehling's Test }\end{array}$ & + & + & + & + \\
\hline $\begin{array}{l}\text { Proteins } \\
. \quad \text { Biuret test } \\
\text { - } \\
\text { Millon's test }\end{array}$ & + & + & + & + \\
\hline $\begin{array}{l}\text { Alkaloids } \\
\text { - } \text { Dragendroff's test } \\
\text { - } \text { Hager's test } \\
\text { - } \text { Mayer's test } \\
\text { - } \text { Wagner's test }\end{array}$ & - & - & - & - \\
\hline $\begin{array}{l}\text { Cardiac Glycoside } \\
\cdot \quad \text { Legal test (Cardenolides) }\end{array}$ & - & - & + & + \\
\hline $\begin{array}{l}\text { Anthraquinone Glycoside } \\
\cdot \text { Borntrager's test } \\
\text { - Schonteten's test for } \\
\text { anthranols } \\
\text { - Modified Borntrager's test }\end{array}$ & - & - & - & - \\
\hline $\begin{array}{l}\text { Cynogenetic Glycoside } \\
\text { - } \quad \text { Guignard test } \\
\text { - } \\
\text { Gercurous nitrate test } \\
\text { Guaiacum test }\end{array}$ & - & - & - & - \\
\hline 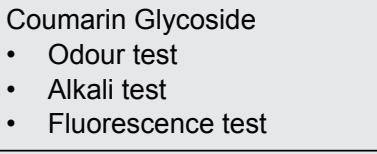 & - & - & - & - \\
\hline $\begin{array}{l}\text { Flavonoids } \\
\text { - } \quad \text { Shinoda test } \\
\text { - } \quad \text { Lead acetate } \\
\text { - }\end{array}$ & + & + & + & + \\
\hline $\begin{array}{ll}\text { Tannins } \\
\text { - } & \text { Ferric chloride }(5 \%) \\
\text { - } & \text { Lead acetate test } \\
\text { - } & \text { Bromine water }\end{array}$ & + & + & + & + \\
\hline 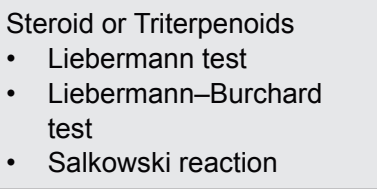 & - & - & + & + \\
\hline $\begin{array}{l}\text { Saponin } \\
\text { - } \quad \text { Foam test } \\
\text { - } \quad \text { Hemolytic test }\end{array}$ & - & - & + & + \\
\hline $\begin{array}{l}\text { Gum } \\
\text { - Swelling test }\end{array}$ & - & - & + & - \\
\hline $\begin{array}{l}\text { Mucilage } \\
\cdot \quad \text { Rhuthenium test }\end{array}$ & - & - & + & - \\
\hline $\begin{array}{l}\text { Fatty Oil } \\
\text { - Filter paper test }\end{array}$ & - & - & - & + \\
\hline $\begin{array}{l}\text { Essential Oil } \\
\text { - Filter Paper test }\end{array}$ & - & - & - & - \\
\hline
\end{tabular}

Note: + means Presence; - means absence 


\begin{tabular}{|c|c|c|}
\hline \multicolumn{3}{|c|}{$\begin{array}{c}\text { Table 2: Total phenolic and flavonoid content of } \\
\text { extracts from host plant- C. halicacabum and } \\
\text { endophytic fungi- } \boldsymbol{D} \text {. spicifera. }\end{array}$} \\
\hline Sample & $\begin{array}{c}\text { Total phenolic } \\
\text { content } \\
\text { (mg of } \text { GAE/g of } \\
\text { extract) }\end{array}$ & $\begin{array}{c}\text { Total flavonoid } \\
\text { content (mg of } \\
\text { RE/g of extract) }\end{array}$ \\
\hline $\begin{array}{c}\text { Endophytic fungi- } \\
\text { D. spicifera culture } \\
\text { extract }\end{array}$ & $22.42 \pm 0.62$ & $12.02 \pm 0.21$ \\
\hline $\begin{array}{c}\text { Endophytic fungi- } \\
\text { D. spicifera aqueous } \\
\text { extract }\end{array}$ & $18.42 \pm 0.57$ & $14.79 \pm 0.43$ \\
\hline $\begin{array}{c}\text { C. halicacabum } \\
\text { aqueous extracts }\end{array}$ & $25.42 \pm 0.82$ & $19.92 \pm 0.34$ \\
\hline $\begin{array}{c}\text { C. halicacabum } \\
\text { methanol extracts }\end{array}$ & $35.82 \pm 0.23$ & $28.71 \pm 0.79$ \\
\hline
\end{tabular}

Table 3: Comparative antioxidant potential of Endophytic fungi- $D$. spicifera extracts, host plantC. halicacabum and biogenic silver nanoparticles.

\begin{tabular}{|c|c|}
\hline Crude extract & $\begin{array}{c}\text { IC }_{50} \text { Value } \\
(\mu \mathrm{g} / \mathrm{mL})\end{array}$ \\
\hline Endophytic fungi- $D$. spicifera culture extract & $45.32 \pm 0.43$ \\
\hline Endophytic fungi- $D$. spicifera aqueous extract & $48.67 \pm 0.09$ \\
\hline C. halicacabum aqueous extracts & $34.56 \pm 0.82$ \\
\hline C. halicacabum methanol extracts & $27.82 \pm 0.28$ \\
\hline Culture extract mediated silver nanoparticles & $18.45 \pm 0.43$ \\
\hline Aqueous extract mediated silver nanoparticles & $20.56 \pm 0.43$ \\
\hline
\end{tabular}

A
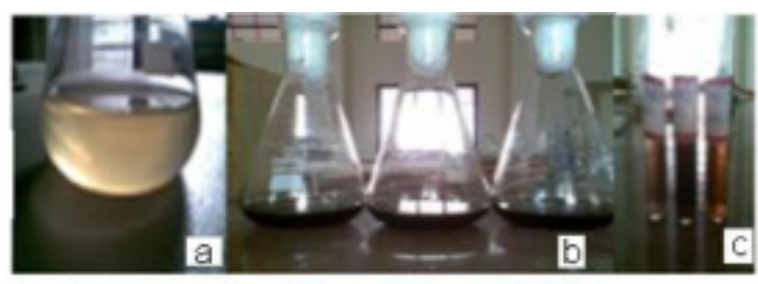

$\mathrm{B}$
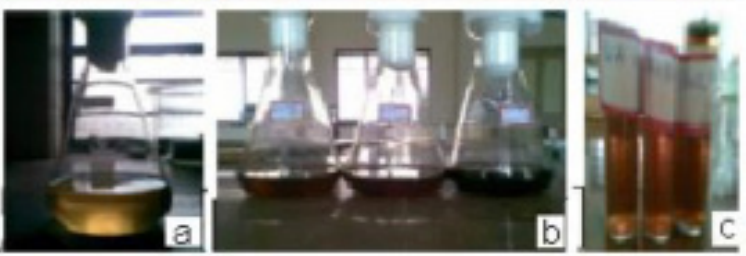

Figure 2: Reaction monitoring of nanoparticle formation by visible analysis.

A: a-Aqueous extract just after addition of silver nitrate; bdark reddish brown coloration in flask shows nanoparticle formation; c- aqueous extracts after $24 \mathrm{hr} \mathrm{B:} \mathrm{a-} \mathrm{Culture} \mathrm{extract}$ just after addition of silver nitrate; b- dark reddish brown coloration in flask shows nanoparticle formation; c- Culture extracts after $24 \mathrm{hr}$.
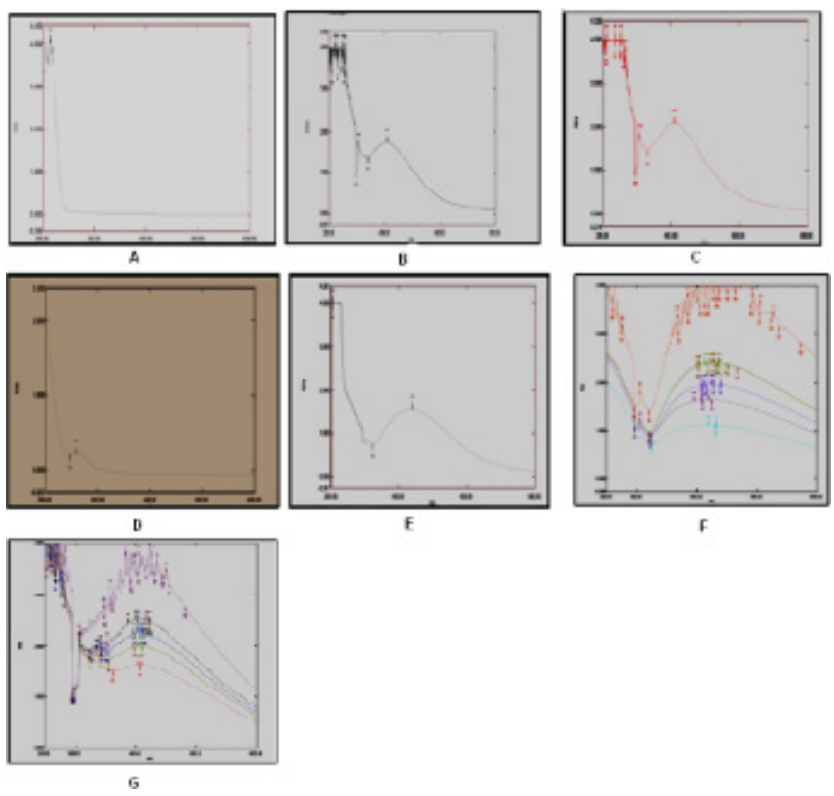

Figure 3: Reaction monitoring of nanoparticles formation by UV-visible spectroscopy.

A: UV-visible spectrum of silver nitrate; B: UV-visible spectrum of solution from reaction flask (Ex) after $24 \mathrm{hr}$; C: UV-visible spectrum of solution from reaction flask (Ex) after $48 \mathrm{hr}$; D: UV-visible spectrum of solution from cell free control flask (Aq) after $24 \mathrm{hr}$; E: UV-visible spectrum of solution from cell free reaction flask after $24 \mathrm{hr}$; F: UV-visible spectrum of solution from cell free extract (Aqueous) reacted with $\mathrm{AgNO}_{3}$ from $24 \mathrm{hr}$ to $216 \mathrm{hr}$; G: UV-visible spectrum of solution from culture extract (Ex) reacted with $\mathrm{AgNO}_{3}$ from $24 \mathrm{hr}$ to $216 \mathrm{hr}$
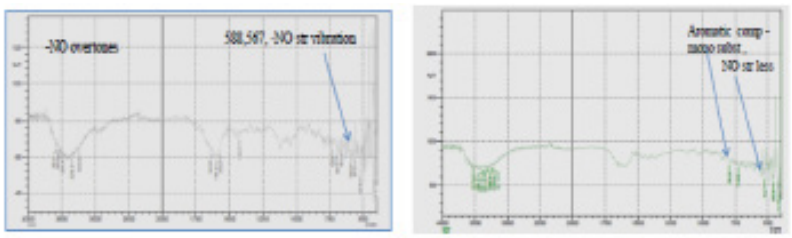

FTIR Spectrum of silver nitrate solution FTIR Spectrum of silver nano-particles on day (1mM)
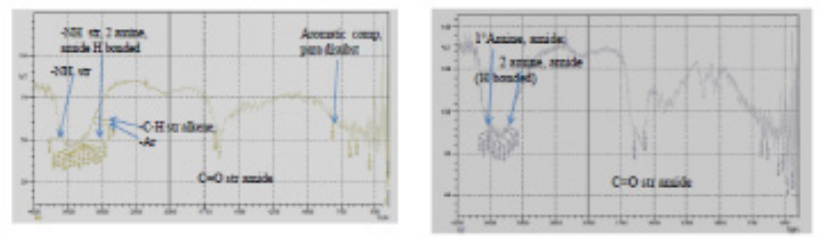

FTIR spectrum of silver nanoparticle produced by culture extract on day 4 .

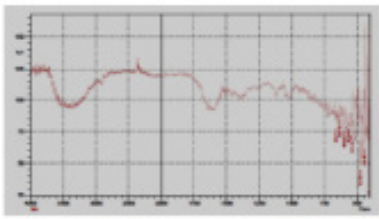

FTIR spectrum of silver nanoparticle biwynthesired from cell free aquesuls extracks FTIR spectrum of silver nanoparticle solution on day 9

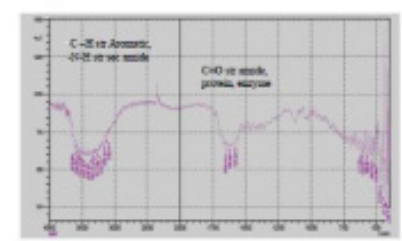

on day 2.

Figure 4: Reaction monitoring of nanoparticles formation by FTIR spectroscopy. 
know size range of nanoparticles as shown in Figure 5. EDX analysis suggested that silver and oxygen are present in the sample; also it confirmed that the sample contains silver nanoparticles. [Figure 6] Scanning Electron Microscopy analysis was performed to study size and surface morphology of the silver nanoparticles synthesized from endophyte extracts [Figure 7]. D. spicifera has shown the ability to biosynthesize nanoparticle by extracellular route i.e by extracts and not outside fungal cells medium in presence of fungi, at room temperature in alkaline conditions at $\mathrm{pH} 9$. Silver nanoparticles were characterised by visible colour change observation. [Figure 2] These findings present a green chemistry approach at room temperature without use of harmful reducing agents. The silver nanoparticle formation process continues for about 9 days, indicating a longer reduction time. In the culture extract (Ex) and cell free aqueous extract (Aq), the biomolecule produced by the endophyte has its reducing property at $\mathrm{pH}$ 9 and temperature around $35-40^{\circ} \mathrm{C}$ as the condition in which the bioreduction event takes place. The UV - visible spectroscopy data [Figure 3] of silver nanoparticle biosynthesized through culture extract and aqueous extract showed surface Plasmon resonance at 406 and $420 \mathrm{~nm}$ within $24 \mathrm{hr}$. The reduction process continues for around 9 days, which was observed due to increase in intensity at their respective $\lambda_{\text {max }}$ values.

A probable mechanism based on the FTIR data [Figure 4] could be the nitration of monosubstituted free hydrophobic group of the (primary amide) of the protein/ enzyme, which leads to change in conformation (secondary amide) exposing the amide bonds to the surface, which play a role in further stabilization beyond day 4 -9. In aqueous extract, amide bonds indicate the role of protein/enzyme in capping. The reduction of metal ion takes place by a nitrate dependent reductase as suggested by in alkaline conditions is confirmed by FT-IR.

The particle size analysis [Figure 5] revealed that separation and purification are important to maintain size uniformity and stabilization to prevent aggregation of silver nanoparticle. The silver nanoparticle biosynthesized by culture extract were polydispersed with maximum concentration of $25-28 \mathrm{~nm}$ size range ( $~ 94-96 \%)$ and an $Z$ average diameter of $193.3 \mathrm{~nm}$ whereas the cell free aqueous extract produced silver nanoparticle of fine particle size with $Z$ average diameter of $50.92 \mathrm{~nm}$ and having maximum concentration of $5.5-6.0 \mathrm{~nm}$ $(\sim 98.2 \%)$. The culture extract mediated nanoparticles showed a negative zeta potential which means that they are charged to maintain stability in solution. Longer

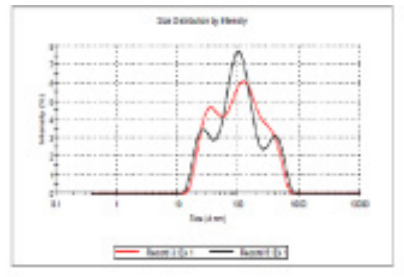

1

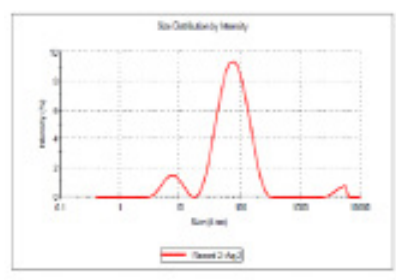

3

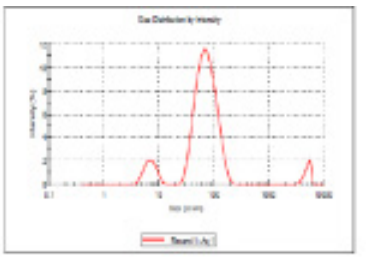

2

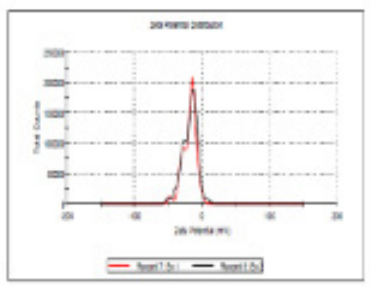

4

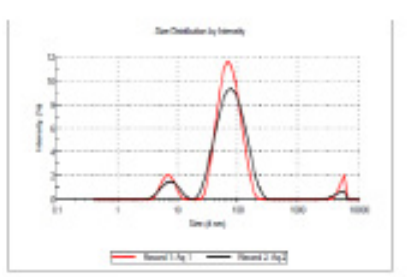

5

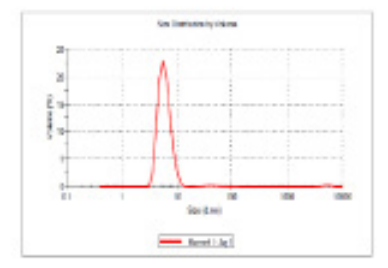

6

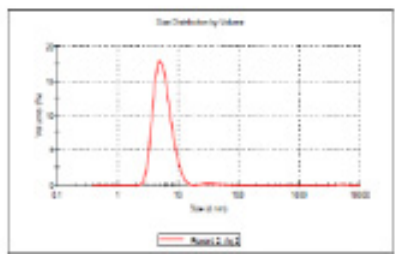

Figure 5: Size measurement of Endophytic fungi - $D$. spicifera mediated silver nanoparticles [Culture Extract-Graph 1 to 4 and Aqueous extract-Graph-5 to 7] by DLS Method.

[Courtesy- SMITA Research Labs, Delhi and IIT-Delhi]

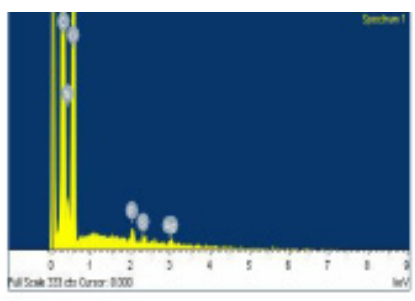

$$
\text { A }
$$

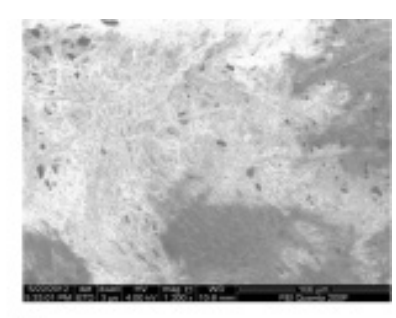

B

Figure 6: EDS spectrum (A) and SEM image $(B)$ of fungal cells exposed to silver nitrate at neutral $\mathrm{pH}$.
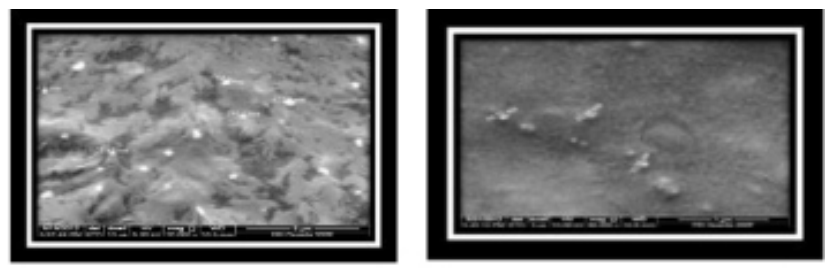

B

Figure 7: SEM images of silver nanoparticles synthesized with D. spicifera. A: AgNP from culture extract at $5.0 \mathrm{kV}, 10.5$ $\mathrm{mm}, 20000 \mathrm{x}$. B: AgNP from aqueous extract at 10,000 kV, $10.6 \mathrm{~mm}, 80000 \mathrm{x}$. 
reduction time is associated with wide variation in particle size distribution.

Dreschlera spicifera, a dermaticious fungi is a known nitrate accumulator ${ }^{12}$ could be the reason why reduction of silver nitrate did not occur. Along with nitrate, uptake of silver from the EDS Figure [Figure 6-7] may explain the presence of competing biomolecule and enzyme for reduction like (NAD or FAD). Concentration of $1 \mathrm{mM} \mathrm{AgNO}$ is insufficient in creating heavy metal stress and the fungus easily survives without any visual morphological change for 1 week. Also, the fungus biomass exhibits stress free survival in heavy metal environment, compared to control with existence only with water molecules. $\mathrm{pH}$ of the medium was around 6-7 after 5 days. Hence biosorption of both silver and nitrate could be taking place, confirmatory analysis on their reduction and nanoparticle formation by the fungi needs to explore.

\section{CONCLUSION}

The design of biosynthetic experiment for faster and complete reduction of silver nitrate by Drechslera spicifera and formation of nanoparticles having uniform size distribution has been developed. Firstly, screening methods have been developed to determine the potential of endophytes to form nanoparticles. Design of experiments to obtain uniform monodispersed and reproducible nanoparticles is also explored to utilize this new source in diverse applications of nanotechnology and its large scale manufacture and use. But the antigenic potential of the nanoparticle should be studied before its incorporation in any application. Study of potential toxicity or fate of nanoparticle in the environment may help in design of synthetic experiments according to green chemistry principles. The results reveal that phenolic and flavonoid content of endophytic fungi isolated from - C. halicacabum are responsible for antioxidant potential and thus for synthesis of silver nanoparticles.

\section{ACKNOWLEDGEMENT}

We would like to thank Head, Department of Botany, Government Vidarbha Institute of Science and Humanity,
Amravati for plant identification; Indian Type Culture Collection Centre, New Delhi for fungi identification and Smita Labs, Delhi as well as IIT, Delhi for their excellent analytical services and communication.

\section{CONFLICT OF INTEREST}

The authors declare no conflict of interest

\section{ABBREVIATIONS}

AgNPs: silver nanoparticles; SEM: scanning-electron microscopy; FTIR: Fourier transform Infrared spectroscopy; DPPH-1: 1-Diphenyl-2-picryl hydrazyl; NAD: Nicotinamide adenine dinucleotide; FAD: Flavin adenine dinucleotide.

\section{REFERENCES}

1. Fedlheim DL, Foss CA. Metal nanoparticles: Synthesis, characterization and applications. CRC Press. 2001.

2. Narayanan KB, Sakthivel N. Biological synthesis of metal nanoparticles by microbes. Adv Colloid Interface Sci. 2010;156(1-2):1-3.

3. Mandal D, Bolander ME, Mukhopadhyay D, Sarkar G, Mukherjee P. The use of microorganisms for the formation of metal nanoparticles and their application. Applied Microbiol Biotech. 2006;69(5):485-92.

4. Rajgopal M. Biodiversity of endophytic fungi associated with Ficus religiosa and Ficus benghalensis. Mycologia Balcanica. 2011;8(2):169-72.

5. Baynesa M, Newcombeb G, Dixonc L, Castleburyc L, O'Donnelld K. A novel plant-fungal mutualism associated with fire. Fungal Biology. 2012;116(1):133-44.

6. Han-MK, Sang-HL, Jung M, Chun SC. A Seed borne Fungus Bipolaris spicifera Detected from Imported Grass Seeds. Plant Pathol J. 2003;19(3):133-7.

7. Netala VR, Kotakadi VS, Bobbu P, Gaddam SA, Tartte V. Endophytic fungal isolate mediated biosynthesis of silver nanoparticles and their free radical scavenging activity and anti microbial studies. 3 Biotech. 2016;6(2):132.

8. Khadabadi SS, Deore SL, Baviskar BA. Experimental Phytopharmacognosy. Second edition. Nirali Prakashan, Pune. 2012.

9. Amudha M, Rani S. Evaluation of in vitro Antioxidant Potential of Cordia retusa. Indian J Pharm Sci. 2016;78(1):80-6.

10. Mandava K. Biological and Non-biological Synthesis of Metallic Nanoparticles: Scope for Current Pharmaceutical Research. Indian J Pharm Sci. 2017;79(4):501-12.

11. Silverstein RM, Bassler GC, Morrill TC. Spectrometric Identification of Organic Compounds. $8^{\text {th }}$ edition, Chichester: John Wiley and Sons. 2011.

12. Baker S, Satish S. Endophytes: Toward a vision in synthesis of nanoparticle for future therapeutic agents. Int J Bio-Inorg Hybd Nanomat. 2012;1(2):67-77. 
PICTORIAL ABSTRACT

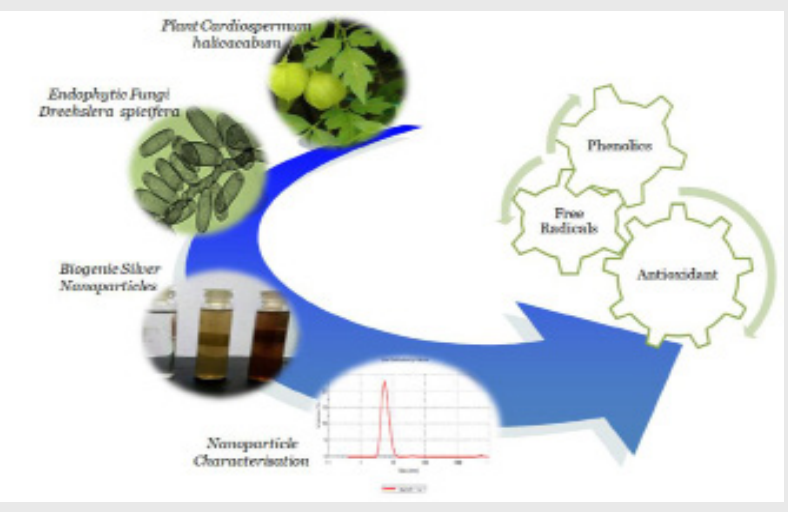

\section{SUMMARY}

- Amravati of Maharashtra has a suitable climatic condition for Drechslera species to exist in endophytic association in plants like Cardiospermum halicacabum L.

- Host plant is found to have more phenolic and flavonoid content compared to endophytic fungi.

- Biogenic silver nanoparticles found to have more antioxidant potential compared to host plant and endophytic fungi while endophytic fungi have slightly lower antioxidant potential compared to host plant.

- The results reveal that phenolic and flavonoid content of endophytic fungi isolated from $C$. halicacabum are responsible for antioxidant potential and thus for synthesis of silver nanoparticles.

Cite this article: Deore SL, Baviskar BA, Sonar PN, Kide AA, Shende BA. Endophytic Fungi, Drechslera spicifera, Mediated Synthesis of Biogenic Silver Nanoparticles. Indian J of Pharmaceutical Education and Research. $2021 ; 55(2 s)$ :s544-s551. 